\title{
Relationships between Arctic Sea Ice and Clouds during Autumn
}

\author{
Axel J. Schweiger AND Ron W. Lindsay \\ Polar Science Center, Applied Physics Laboratory, University of Washington, Seattle, Washington
}

\author{
Steve Vavrus
}

Center for Climate Research, University of Wisconsin-Madison, Madison, Wisconsin

\author{
JENNIFER A. FranCIS \\ Institute of Marine and Coastal Sciences, Rutgers, The State University of New Jersey, New Brunswick, New Jersey
}

(Manuscript received 24 July 2007, in final form 11 December 2007)

\begin{abstract}
The connection between sea ice variability and cloud cover over the Arctic seas during autumn is investigated by analyzing the 40-yr ECMWF Re-Analysis (ERA-40) products and the Television and Infrared Observation Satellite (TIROS) Operational Vertical Sounder (TOVS) Polar Pathfinder satellite datasets. It is found that cloud cover variability near the sea ice margins is strongly linked to sea ice variability. Sea ice retreat is linked to a decrease in low-level cloud amount and a simultaneous increase in midlevel clouds. This pattern is apparent in both data sources. Changes in cloud cover can be explained by changes in the atmospheric temperature structure and an increase in near-surface temperatures resulting from the removal of sea ice. The subsequent decrease in static stability and deepening of the atmospheric boundary layer apparently contribute to the rise in cloud level. The radiative effect of this change is relatively small, as the direct radiative effects of cloud cover changes are compensated for by changes in the temperature and humidity profiles associated with varying ice conditions.
\end{abstract}

\section{Introduction}

This study is motivated by the need to understand potential linkages between sea ice and cloud cover. Sea ice extent has decreased markedly over the last few decades (Cavalieri et al. 2003; Serreze et al. 2007, 2003). The more recent (since 1988) decrease is thought to be the result of the combined effects of gradual warming, changes in the atmospheric and oceanic circulation patterns, and the ice-albedo feedback (Lindsay and Zhang 2005). Other studies implicate changes in downwelling longwave radiation as the primary driver for decreases in sea ice (Francis and Hunter 2006). In the context of sea ice albedo feedback, autumn is a particularly important season. Heat gained by the Arctic Ocean during the summer is lost to the atmosphere during the

Corresponding author address: Axel Schweiger, Applied Physics Laboratory, University of Washington, 1013 NE 40th Street, Seattle, WA 91105.

E-mail: axel@apl.washington.edu time of rapid increase in ice extent from the September minimum through November. Mechanisms that control this heat loss during autumn, and that allow some of the excess summer heat to remain in the ice ocean system, are necessary to perpetuate the ice-albedo feedback into the next melt season. Cloud cover and its capacity to substantially modify the surface radiation balance clearly has the potential to be one such mechanism. Moreover, changes in sea ice potentially affect cloud cover by modifying heat and moisture exchanges between the surface and atmosphere. As the climate warms, expected changes in sea ice are likely to affect both the overlying cloud cover and the overall surface heat balance. It is therefore important to understand whether and how sea ice and cloud cover interact, and to verify that these processes are appropriately represented in climate models. This study represents a first step in this direction.

Our approach is to use a composite analysis technique to assess whether the interactions between sea ice and clouds are similar in both satellite products and 
atmospheric reanalysis data. If the reanalysis model captures these aspects of the observed variability, then the physical mechanisms linking sea ice and cloud cover can be analyzed using the reanalysis fields. Recognizing that both data sources carry potentially large errors, commonalities in the observed covariability secondarily enhances confidence in both datasets. Our focus here is entirely on autumn [September-November (SON)] because during this time 1) the interannual sea ice variability is greatest and 2) the role of clouds in modifying the surface heat balance is of particular interest. Our goal is to document the statistical relationship between sea ice and clouds and gain some insights into the physical mechanisms driving this link. Note that this study is limited to the connection between sea ice and cloud cover. The relevance of other processes in controlling cloud cover variability is a broader question that is considered elsewhere (e.g., Liu et al. 2007).

\section{Background}

Though subject to considerable speculation, very little is known about the connection between sea ice and cloud variability. Sea ice is known, however, to play a role in the various mechanisms that have been proposed over the years to explain the large annual cycle of clouds over the Arctic Ocean, which is characterized by fewer clouds during winter than summer (see Beesley and Moritz 1999 for a review). Prevailing theories are 1) air mass modification: moist, warm air from the warmer continents (summer) is advected over the colder sea ice, where it cools to saturation; 2) lack of moisture source: during winter the pack ice cannot provide sufficient moisture to maintain the large cloud amounts in the boundary layer owing to low evaporation/sublimation rates and the strongly stratified temperature profile; and 3) crystalline precipitation: ice crystal precipitation from clouds due to very low temperatures over the sea ice during winter reduces the winter cloud amount. Beesley and Moritz (1999) favor the latter theory to explain the seasonal cycle. However, more recent results using ground-based lidar and radar data from the Surface Heat Budget of the Arctic Experiment (SHEBA) field campaign suggest that previous analyses based on meteorological surface observations may actually underestimate winter cloud cover by as much as $30 \%$ (Intrieri et al. 2002; Schweiger et al. 2002). The amplitude of the annual cycle, therefore, appears to be considerably smaller than previously thought.

Global climate model (GCM) simulations for enhanced greenhouse gas scenarios span a spectrum of responses in both sign and magnitude for what will hap- pen to Arctic clouds as the climate warms and sea ice melts (Holland and Bitz 2003). However, most models used for the Intergovernmental Panel on Climate Change (IPCC) Fourth Assessment project exhibit increases in annual average cloud cover in the Arctic (Vavrus et al. 2008, manuscript submitted to Climate Dyn.).

Data and modeling results from the Beaufort and Arctic Storms Experiment (BASE) during 1994 provided the first detailed information on the characteristics and evolution of Arctic clouds during autumn. Case studies from this experiment, though limited in scope, provide useful clues to the interpretation of autumn cloud variability under investigation in the present study.

Results from SHEBA, the First International Satellite Cloud Climatology Project (ISCCP) Regional Experiment-Arctic Cloud Experiment (FIRE-ACE), and more recently from the Mixed Phase Arctic Cloud Experiment (M-PACE) have provided valuable insights into the composition and physical processes governing the formation of Arctic clouds as well as highlighted the need for improved models of cloud microphysics to characterize prevalent mixed-layer clouds. These observational and modeling studies have focused on local scales and are single-year studies that provide little information about the impact of sea ice variability on Arctic clouds. The present study is designed to bridge the gap between these field campaigns and global-scale GCM model experiments.

\section{Methodology}

To investigate the link between sea ice and cloud cover, a compositing technique is used that avoids the assumption of a linear relationship underlying many other techniques, such as linear correlation analysis. We compute composites of cloud amount and other related variables corresponding to local (i.e., in the same grid cell) sea ice conditions. Let $\operatorname{IC}(x, y, i)$ be the sea ice concentration at location $(x, y)$ in the autumn of year $i, \overline{\mathrm{IC}}(x, y)$ is the temporal mean value of $\operatorname{IC}(x, y, i)$, and $\sigma(x, y)$ is its temporal standard deviation. Let $k_{+}$ be the collection of years that satisfy $\operatorname{IC}\left(x, y, k_{+}\right)>$ $\overline{\mathrm{IC}}(x, y)+1 / 2 \sigma(x, y)$, and $N_{+}$is the number of years in this collection. Similarly, $k_{-}$is the collection of years that satisfy $\operatorname{IC}\left(x, y, k_{-}\right)<\overline{\mathrm{IC}}(x, y)-1 / 2 \sigma(x, y)$, and $N_{-}$is the number of these years. We define high and low composites as

$$
\begin{aligned}
& S_{+}(x, y)=\frac{1}{N_{+}} \sum_{k_{+}} V\left(x, y, k_{+}\right), \\
& S_{-}(x, y)=\frac{1}{N_{-}} \sum_{k_{-}} V\left(x, y, k_{-}\right),
\end{aligned}
$$


where $V$ is the variable to be composited (e.g., cloud fraction).

Because the composites are based on local information from the same grid cell, adjacent grid points in the composites do not necessarily contain averages over the same subset of years. Local composites, rather than those formed by using a global measure of sea ice variability (e.g., Northern Hemisphere ice extent), are used because sea ice variability has considerable spatial heterogeneity with substantial asymmetries around the basin. Ice concentration anomaly maps are compared to those of the composited variable (e.g., cloud fraction, static stability). The prevalence of wide areas of the same sign in the composites is interpreted as a connection between sea ice and the composited variable. In essence, the compositing method simply compares heavy ice years with light ice years and the corresponding local conditions. Because there is no reason to expect a linear relationship between variability in sea ice and cloud cover, a compositing technique is preferred over linear correlation.

The composites were tested for statistical significance using the following tests. The difference of the areaaveraged "global" means $\bar{S}_{+}=\left(1 / N_{x} N_{y}\right) \sum_{x=1, y=1}^{N_{x} N_{y}} S_{+}$ $(x, y)$ and $\bar{S}_{-}=\left(1 / N_{x} N_{y}\right) \sum_{x=1, y=1}^{N_{x} N_{y}} S_{-}(x, y)$ was tested for the null hypothesis $\mathrm{H}_{\mathrm{o}}: \bar{S}_{+} \neq \bar{S}_{-}$where $x, y$ are the subset of points that define our study area [ice concentration standard deviation $\sigma(x, y)>10 \%]$. To address the spatial autocorrelation in the composite fields, we conducted Monte Carlo simulations to build an ensemble of random composites. Distributions of differences were generated by randomizing time of the variable $V$ being composited. This procedure retains the spatial autocorrelation in the field. Distributions were used to reject $\mathrm{H}_{\mathrm{o}}$ at the 0.99 significance level for all the computed composites. In addition, we test for field significance of each composite following a procedure outlined by Livezey and Chen (1983). The procedure tests at each grid point the local null hypothesis $\mathrm{H}_{\mathrm{o}}: S_{+}(x, y)=S_{-}(x, y)$ using a $t$ test. The fraction of grid points where the local null hypothesis is rejected at the 0.95 level is then compared to the number of grid points that can be expected from a random distribution established through the Monte Carlo simulation describe above. The results of the global means tests $\left(P_{g}\right)$ and field significance tests $\left(P_{f}\right)$ are given in the figure captions.

\section{Datasets}

Cloud cover retrieval from satellites over snow and ice surfaces is an ongoing research topic. Progress toward improving retrievals has been made and several useful datasets over the Arctic Ocean are now available (Key 2000; Maslanik et al. 2001; Schweiger et al. 1999). The Radiative Transfer for the Television and Infrared Observation Satellite (TIROS) Operational Vertical Sounder (TOVS) Polar Pathfinder (TPP) dataset (Schweiger et al. 2002) is derived from the High Resolution Infrared Radiation Sounder (HIRS) and Microwave Sounding Unit (MSU) instruments aboard the National Oceanic and Atmospheric Administration (NOAA) polar-orbiting platforms and is available for the period 1980-2004. Validation results (Schweiger et al. 2002) show a good correlation (0.7) of cloud fraction from the TPP dataset as compared with surface observations from the SHEBA field campaign in the Beaufort Sea.

Reanalysis products from the 40-yr European Centre for Medium-Range Weather Forecasts (ECMWF) ReAnalysis (ERA-40) project (Uppala et al. 2005) were obtained from the archive residing at the National Center for Atmospheric Research (NCAR; Comeaux and Worley 2005). Surface, vertically integrated fields, and upper-air variables were obtained at model spatial resolution (corresponding to about $1^{\circ}$ ). The data were then regridded to a $40-\mathrm{km}$, equal-area grid using linear interpolation, and averaged for each season [DecemberFebruary (DJF), March-May (MAM), June-August (JJA), and SON].

Ice concentrations used in this study are from the ERA-40 product, which in turn are derived from the Hadley Centre Sea Surface Temperature (SST-1) dataset (1958-81) and thereafter from the weekly NOAA/National Centers for Environmental Prediction (NCEP) two-dimensional variational data assimilation (2DVAR) dataset. This product is based on observations from the Scanning Multichannel Microwave Radiometer (SMMR) and Special Sensor Microwave Imager (SSM/I) passive microwave retrievals (Uppala et al. 2005). The ERA-40 cloud model includes prognostic equations for cloud liquid water and ice and cloud fraction (ECMWF 2003; Tiedtke 1993). Mixed-phase clouds are represented by an ice/water fraction, which is a simple function of temperature. Cloud fraction is determined at each model level and then integrated vertically into three broad layers and total cloud amount using a maximum-random-overlap assumption. The ERA-40 model has a hybrid sigma-pressure coordinate system, and cloud amounts in the layers correspond to sigma coordinates below 0.8 (low), between 0.8 and 0.45 (middle), and greater than 0.45 (high). Assuming a $1000-\mathrm{hPa}$ surface pressure, these layers correspond to $1000-800 \mathrm{hPa}, 800-450 \mathrm{hPa}$, and $450 \mathrm{hPa}$ and above. Because upper-level clouds obscure the under- 

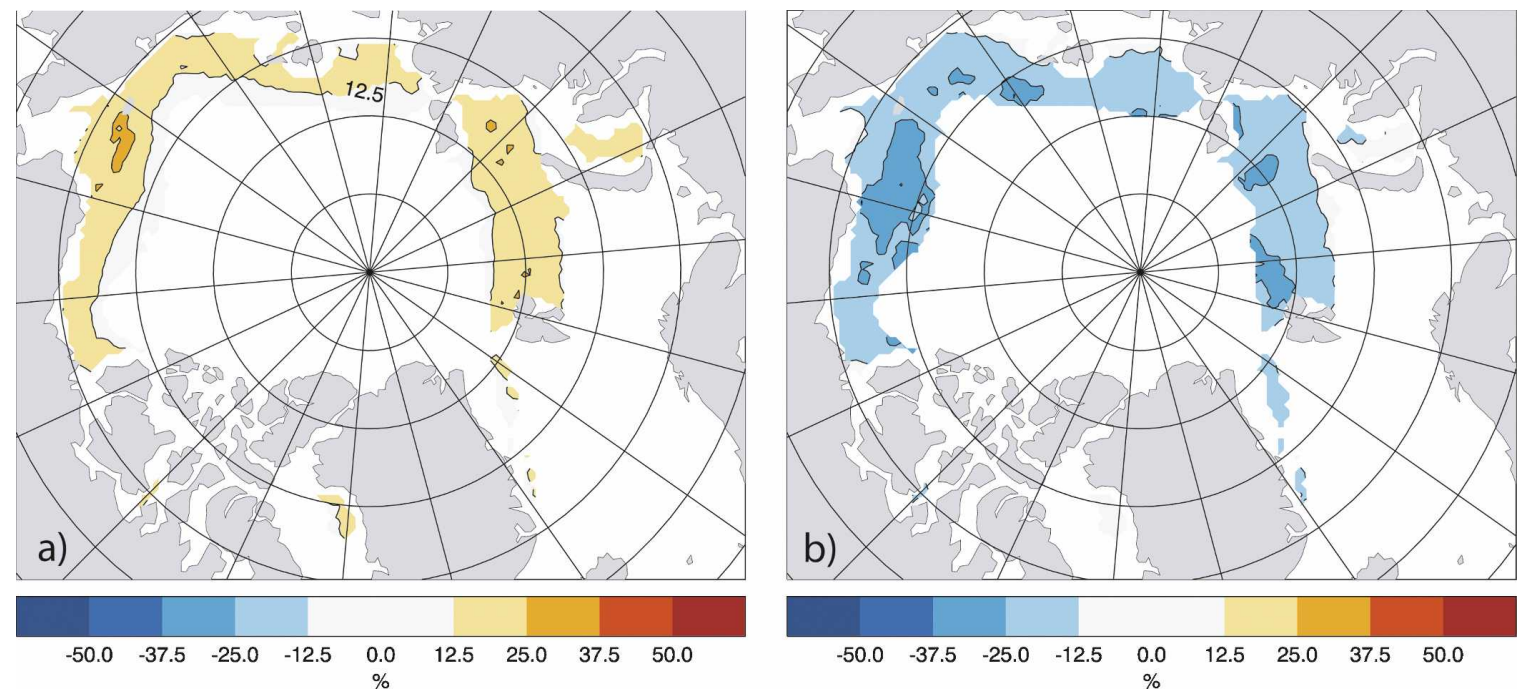

FIG. 1. Anomaly composites of ice concentration from ERA-40 during autumn (SON) for the period 1980-2001 showing the spatial pattern and the magnitude of ice concentration anomalies. Anomalies at each point are computed for years with ice concentrations (a) more and (b) less than one-half std dev of the interannual ice concentration anomaly at each individual grid point. Areas with ice concentration standard deviations below $10 \%$ from year to year are masked out.

lying lower clouds from satellite, relative changes in low and upper cloud amount cannot be observed. For comparison with the ERA-40 data, cloud amounts from TPP for all clouds above $800 \mathrm{hPa}$ were computed based on retrieved cloud-top heights and are referred to as upper clouds.

\section{Results}

\section{a. Is there a link between sea ice and cloud cover?}

Figure 1 presents composites of ice concentration anomalies computed from the ERA-40 product. Composites represent grid points with ice concentrations that deviate by more than one-half standard deviation from the mean autumn (SON) ice concentration for the period 1980-2001. Areas with standard deviations less than $10 \%$ are not considered and are masked in the figures. This restricts our analysis to the marginal ice zone where sea ice variability is greatest and thus the likelihood of detecting a sea ice signal in the cloud cover data is enhanced. The composites exhibit the expected pattern of anomalies around the ice margins, with greatest variability in the western part of the Arctic just north of Bering Strait.

Ice concentration composites at each grid point are then used to generate corresponding composites of low cloud fraction (Fig. 2), which produces a pattern with close resemblance to that for the ice concentration shown in Fig. 1. Higher ice concentrations are associated with greater low cloud amounts, while lower ice concentrations are be associated with fewer low clouds.
Low cloud amounts vary by $\sim 12 \%$ for a corresponding $40 \%$ variation in ice concentration. Note that cloud observations are not assimilated into the reanalysis.

The equivalent pattern in ERA-40 midlevel clouds is shown in Fig. 3. The composite pattern is nearly opposite to that for low clouds. Higher ice concentrations are associated with fewer middle clouds; lower ice concentrations are associated with an increase in middle cloud fraction. These results implicate a link between clouds and local changes in sea ice, suggesting that lower ice concentrations are associated with an increase in cloud height.

A similar relationship between cloud-height change and sea ice variability is apparent in the same analysis but with cloud products retrieved from the TPP dataset. Figure 4 shows a similar decrease in TOVS upper-level clouds associated with greater ice concentrations, as seen in the ERA-40 middle clouds. Composites of TOVS midlevel clouds corresponding to the definition in the ERA-data (not shown) show a very similar pattern except for a few small areas indicating an opposite connection between sea ice and midlevel clouds, which seems to arise from the fact that high clouds can obscure middle clouds. The consistency in patterns of correspondence between sea ice and cloud height from both satellite and reanalysis data provides additional confidence in the following conclusions: 1 ) the strength of the relationship exceeds any errors in either data source; 2) the physical processes involved in this relationship are well represented in the reanalysis, and other processes, such as cloud-aerosol interactions that 

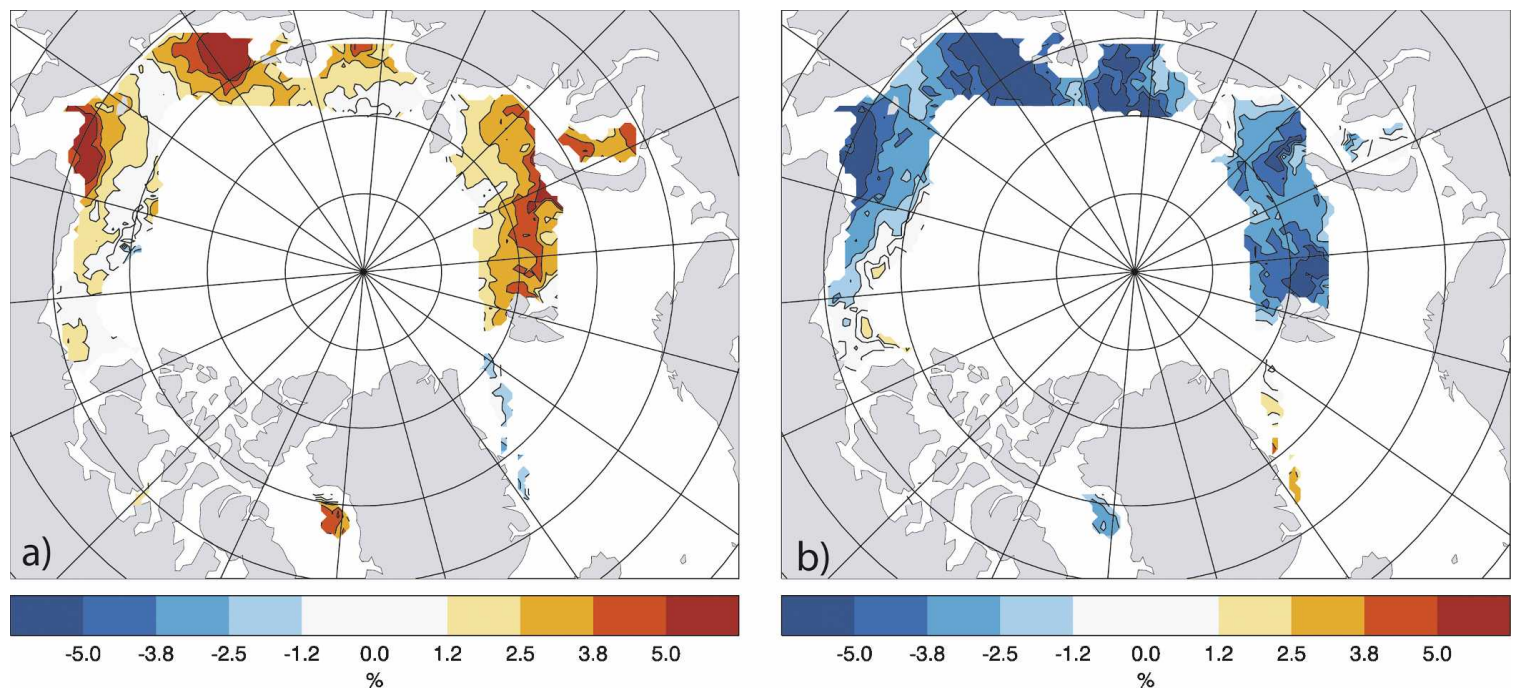

FIG. 2. Anomaly composites of low cloud fraction from ERA-40 corresponding to the sea ice anomalies shown in Fig. 1 Anomalies correspond to cases where ice concentrations (a) exceed $0.5 \sigma$ of interannual variability and (b) are below $0.5 \sigma\left(P_{g}>0.99, P_{f}>0.99\right)$.

are not included in the reanalysis, do not contribute substantially to this relationship; and 3) a careful diagnosis of the surface and atmospheric conditions in the reanalysis data should reveal the physical processes responsible for the observed statistical relationship.

\section{b. Physical explanation: Changes in boundary layer structure}

At first glance, the observed connection between sea ice and clouds appears counterintuitive. One might think that increased moisture fluxes from areas of reduced sea ice would increase low-level clouds rather than reduce them. The results of this analysis, however, do not support this intuition. One physical mechanism that might explain the observed sea ice-cloud link lies in the change in vertical temperature structure associated with the retreat of sea ice. When there is less sea ice (which could be dynamically and/or thermodynamically driven), low-level atmospheric temperatures in autumn are higher. Figure 5 shows a composite of ERA-40 temperature profiles corresponding to locations with above $(>0.5 \sigma)$ and below $(<0.5 \sigma)$ normal ice concentrations during SON. The profile composites show that in cases with above-normal sea ice concentrations, surface temperatures are lower by about $3 \mathrm{~K}$, and a weak surface-based temperature inversion exists

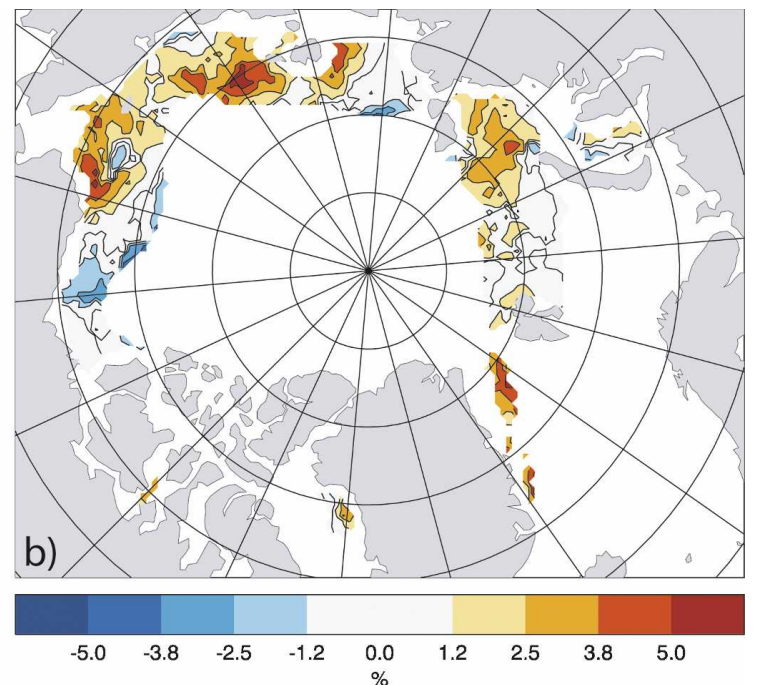

FIG. 3. Same as Fig. 2 but for middle clouds, also from the ERA-40 model $\left(P_{g}>0.99, P_{f}>0.99\right)$. 

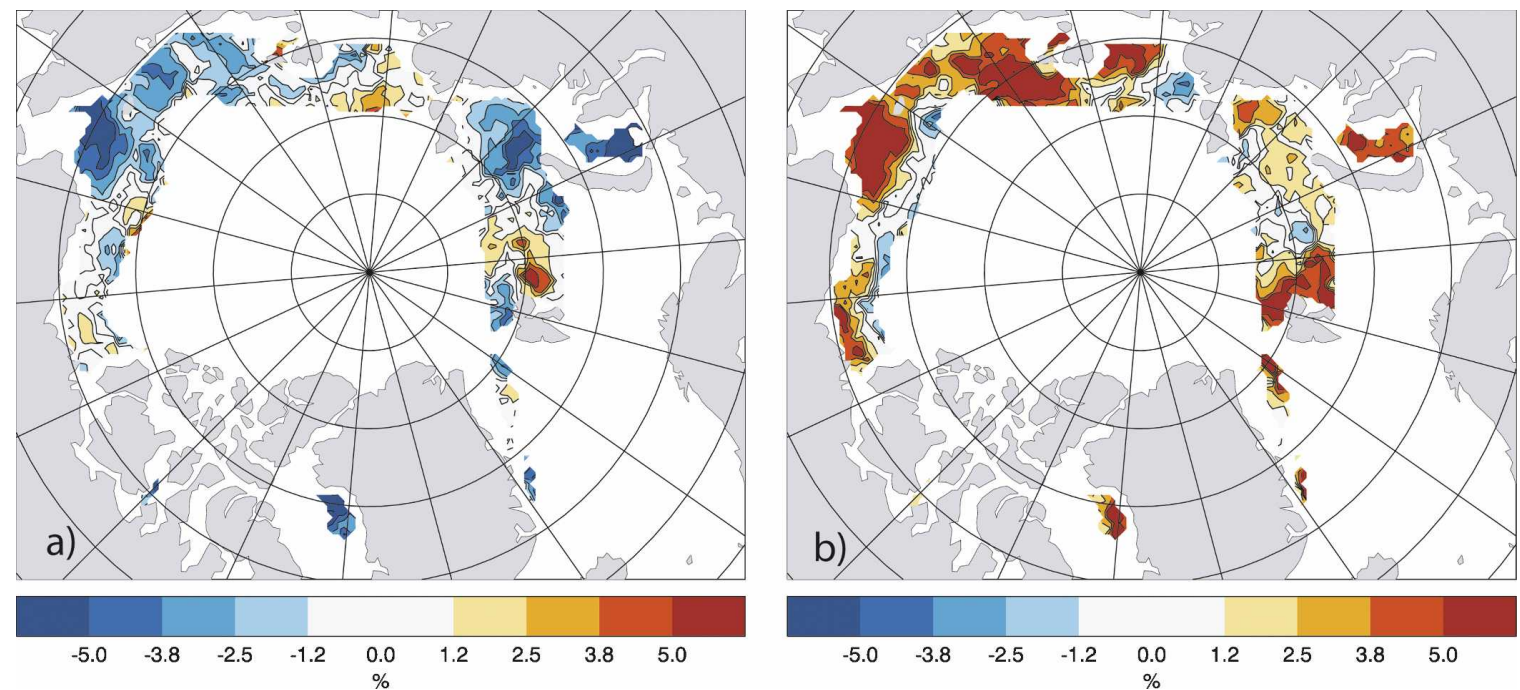

FIG. 4. Composites of upper (above $800 \mathrm{hPa}$ ) cloud amount obtained from the TPP dataset for (a) above- and (b) below-normal ice concentrations $\left(P_{g}>0.99, P_{f}>0.98\right)$.

in the composite at about $850 \mathrm{hPa}$. In conditions with below-normal ice concentrations, low-level temperatures are higher and the surface-based inversion is absent from the composites. Figure 6 shows the spatial patterns of this change as manifested in the $850-\mathrm{hPa}$ static stability, defined as the potential temperature difference between $850 \mathrm{hPa}$ and the surface. Static stability is greater where ice concentrations are above normal and smaller where ice concentrations are below normal. Klein and Hartmann (1993) have shown that the occurrence of stratus clouds over global oceans is strongly correlated with static stability. Their physical explanation is that the boundary layer stratification provides an indication of low-level inversions that tend to cap convection and confine moisture and cloud tops within the boundary layer. The Arctic was the only region where their theory did not apply, but this may be because their focus was on explaining the annual cycle of cloudiness. Other processes, such as air mass modification, may sometimes dominate in the Arctic. It appears, however, that intraseasonal variations in Arctic low clouds are indeed tied to static stability, and Arctic stratus over the ice-free marginal ice zone may be behave more like midlatitude marine stratus.

Other evidence from modeling and observational Arctic case studies, though mainly focused on the summer season, provides further support for the observed link between sea ice and cloud cover. Herman and Goody (1976), for example, attribute the persistence of summer Arctic stratus clouds to the lack of dissipative processes in a numerical model. During spring and fall, sensible heat flux from the ocean may warm the boundary layer by convective processes, which creates condi- tions unfavorable for the maintenance of low Arctic stratus clouds. Observational evidence from a study relating the occurrence of summer stratus over the Arctic suggests that a significant correlation exists between

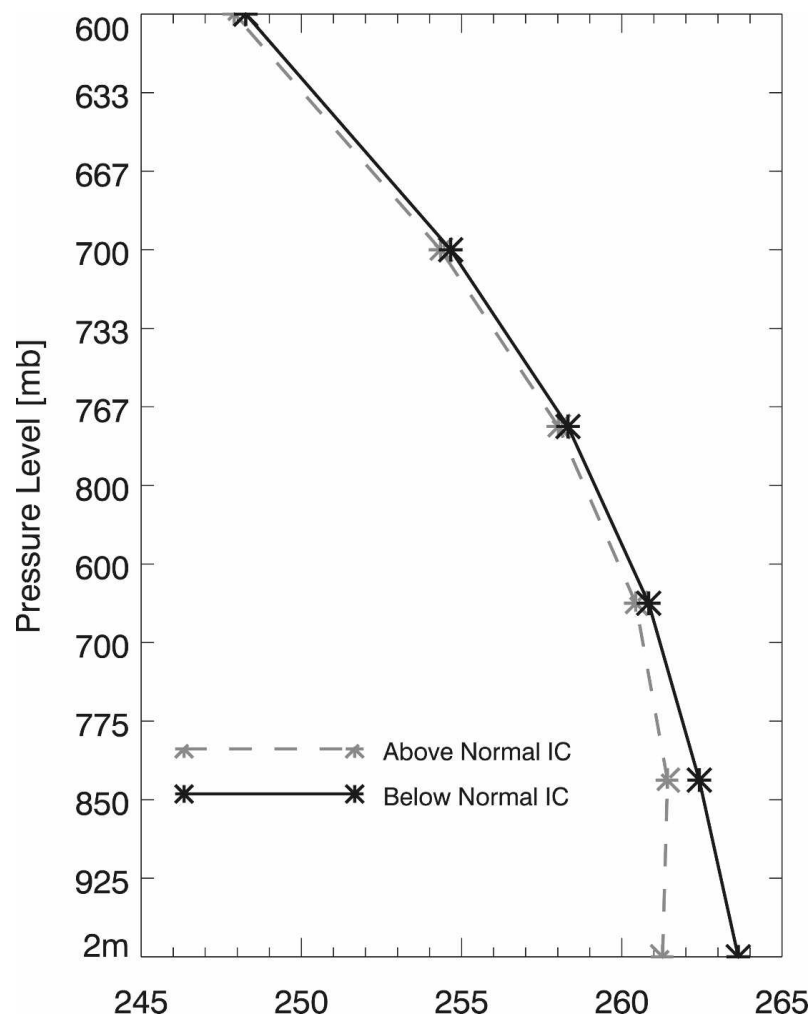

FIG. 5. Composites of temperature profiles for locations with above-normal $(+0.5 \sigma)$ and below-normal $(-0.5 \sigma)$ ice concentrations from ERA-40. 

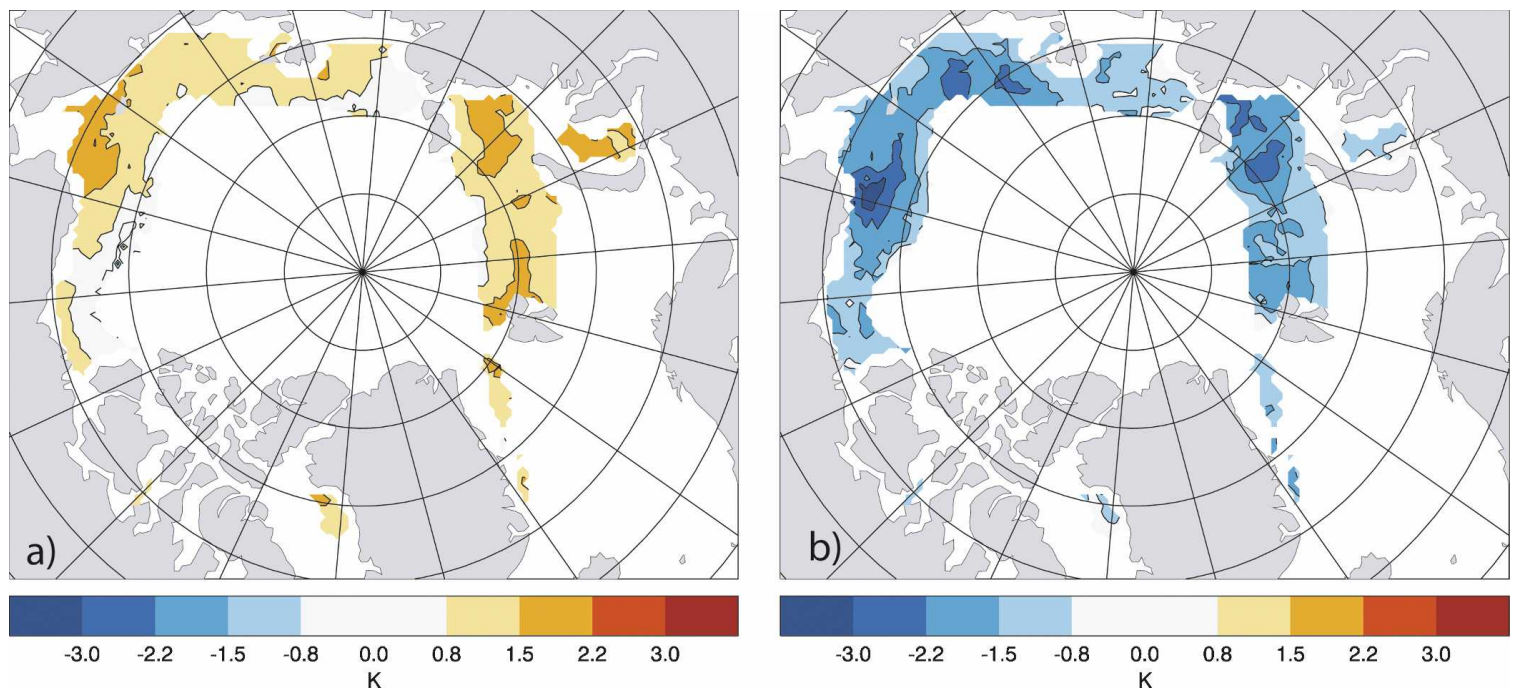

FIG. 6. Composites of static stability (potential temperature at $850 \mathrm{hPa}$-surface) for (a) above- and (b) below-normal ice concentration $\left(P_{g}>0.99, P_{f}>0.99\right)$. Data are from ERA $=40$.

temperature differences in the layer from $850 \mathrm{hPa}$ to the surface and the occurrence of clouds (Curry and Herman 1985). Tsay and Jayaweera (1984), using aircraft data taken over the Beaufort Sea in June 1980, find Arctic stratus clouds present in a wide range of meteorological conditions. In one of their case studies, where flow was northwesterly from ice-covered areas, the cloud-top height increased as air traveled over the open water. Aircraft data gathered during BASE also support the association of autumn stratus clouds with strong static stability and temperature inversions occurring either above or within the cloud decks (Curry et al. 1997; Pinto 1998). Further support for the idea that cloud cover over the open water or broken sea ice would be less than that over the pack ice comes from a BASE flight during 12 October 1994 when over the open water/broken sea ice south of the ice edge, cloud fraction was in the order of $80 \%$ and of stratocumulus type. Over the ice pack north of the marginal ice zone, clouds were of stratus type with nearly $100 \%$ coverage and larger temperature differences between the surface and cloud top. Curry et al. (1997) suggest that air advected from Canada, where temperatures were colder at that time, was warmed and moistened over the open water. The air then cooled as it traveled northward over the pack ice, leading to cloud formation. Wang and Wang (2004) investigate the boundary layer structure of clear and cloudy regions during BASE. They find that the boundary layer is saturated in both regions, and in clear conditions it is shallow $(200 \mathrm{~m})$ and more spatially homogeneous. The presence of leads in the clear regions did not provide detectable levels of additional condensate. They attribute the clear/cloudy dif- ference to local small-scale variations in either temperature or humidity. Paluch et al. (1997), however, also analyze data from BASE and find that open-ocean areas tend to have well-mixed boundary layers that are often cloudy. Sea ice areas, in contrast, tend to have fewer clouds. If clouds were present over sea ice, they were decoupled from the surface with stable layers below the clouds.

A modeling study of the effect of sea ice on the development of boundary layer roll clouds during cold-air outbreaks (Liu et al. 2006) indicates that the presence of sea ice limits convection and the development of such clouds, while a decrease in sea ice concentration leads to an increase in this type of cloud. These apparent conflicts with our present findings (more rather than fewer clouds associated with sea ice) demonstrate the complexity of the processes involved and highlight the need to expand the limited spatial and temporal scale of typical field studies through the analysis of longer time series with greater spatial coverage.

Our explanation for the observed link between sea ice and cloud cover (rise in cloud levels) is also supported by the corresponding behavior of several other variables. Changes in sea ice cover are expected to change turbulent fluxes from the ocean to the atmosphere. The magnitude of these fluxes depends on, among other things, the vertical gradients in temperature and humidity between the surface and atmosphere. Figure 7 shows relative humidity composites for cases in which ice concentration is above and below normal. This pattern is also consistent with the observed changes in ice concentration and cloud cover. Surfacelevel humidity is greater (lower) when ice concentra- 

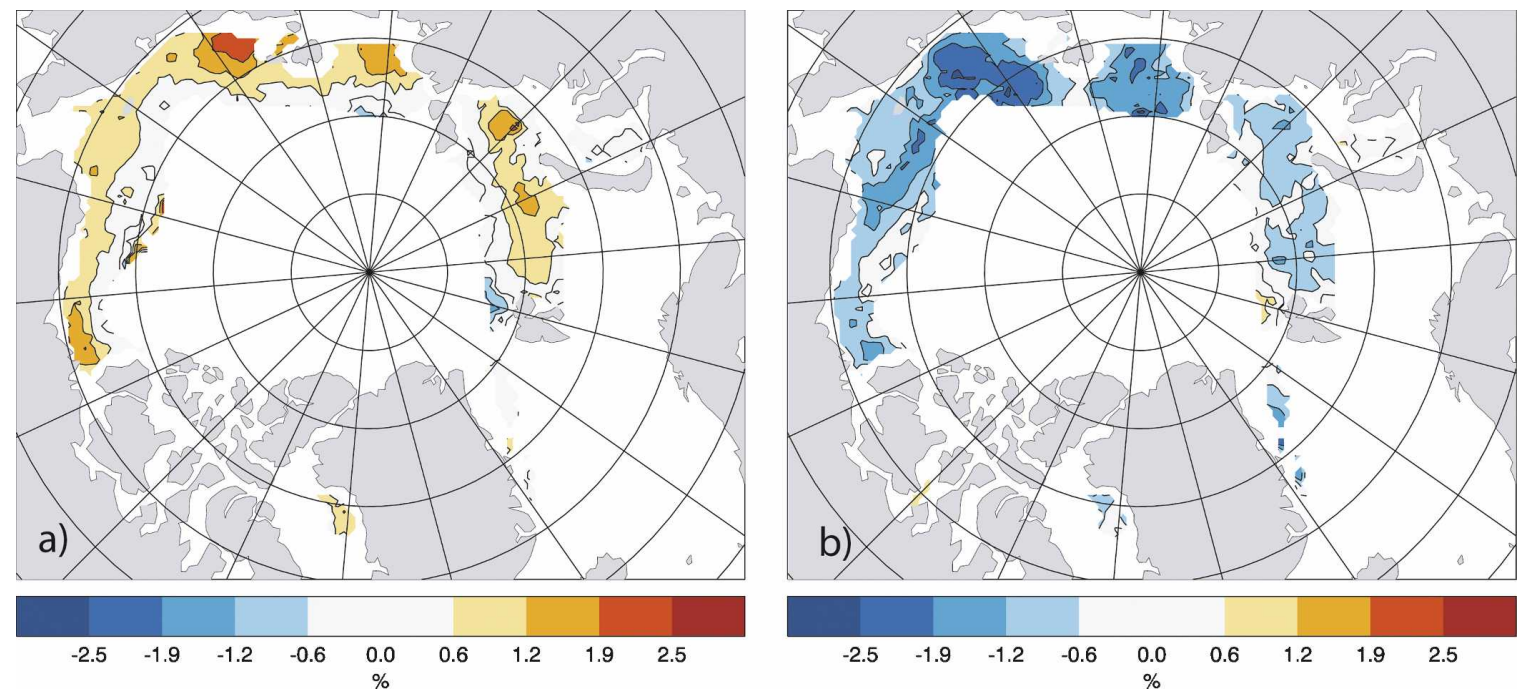

FIG. 7. Same as Fig. 6, but for composites of relative humidity on sea ice concentration $\left(P_{g}>0.99, P_{f}>0.99\right)$.

tions are lower (higher). This connection between sea ice cover and relative humidity suggest that the removal of ice has a larger effect on air temperature than on specific humidity, leading to a reduced saturation of the boundary layer. The upper part of the boundary layer, meanwhile, is moistened owing to increased convection (Fig. 8). The height of the boundary layer, computed using a bulk Richardson method and provided in the ERA-40 model archive (ECMWF 2003), also increases by as much as $300 \mathrm{~m}$ in below-normal ice concentrations relative to above-normal ice concentration composites (Fig. 9). The increased height has the effect of distributing available moisture over a deeper layer of the atmosphere.

Evidence for increased convection over open water areas is supported by changes in precipitation. Less (more) precipitation is associated with ice concentrations above (below) normal. This pattern (not shown) is apparent in both the large-scale and in the ERA-40 convective precipitation. Interestingly, even though temperatures are higher when ice concentrations are lower, temperatures remain low enough that most of the precipitation during autumn still falls as snow, yielding an increase in snowfall when ice concentrations are lower (Fig. 10). Though the variation in precipitation associated with ice concentration change is small (about $1 \%$ of the monthly mean), increases in precipitation may play a role in the observed dissipation of low-level clouds (Herman and Goody 1976).

\section{c. Relevance: Impact on the surface heat balance}

These results reveal an apparent connection between sea ice variability and cloud cover. What role does this

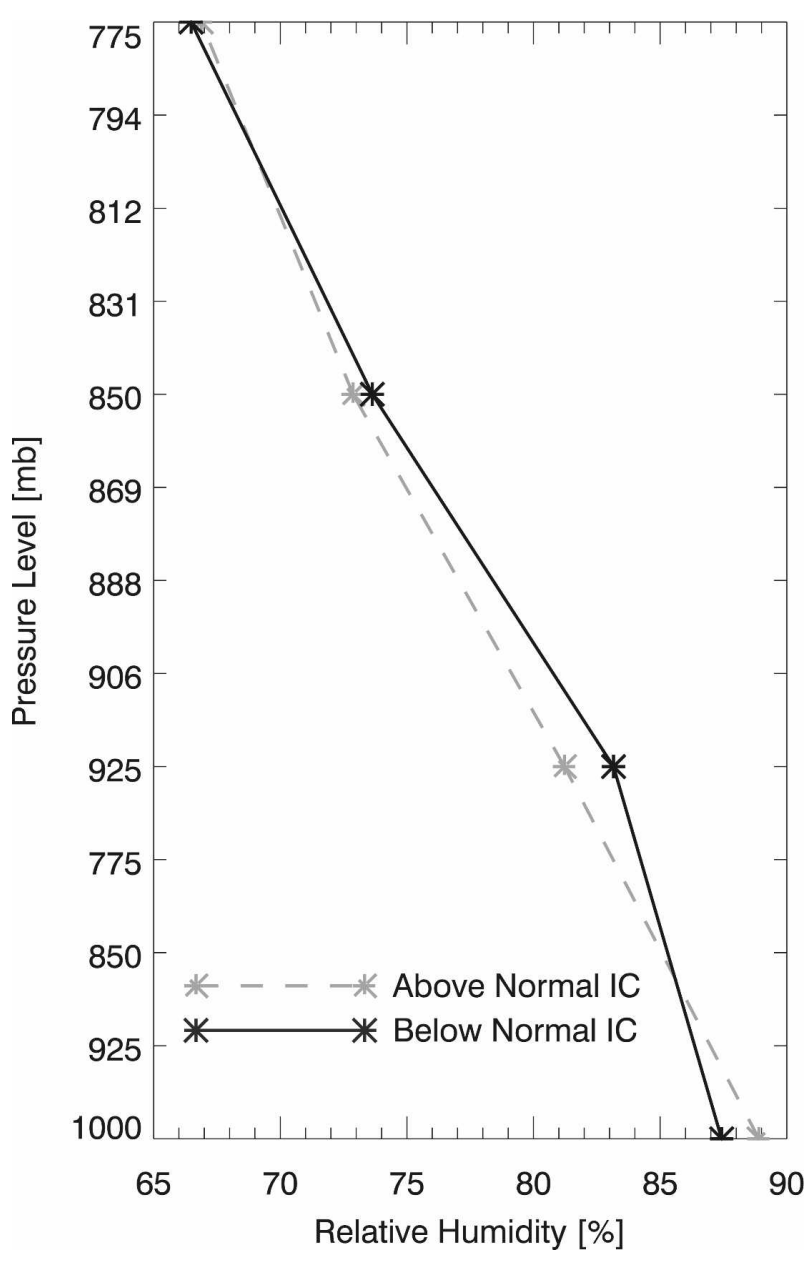

FIG. 8. Relative humidity profile composites from ERA-40 for above- and below-normal ice concentration. 

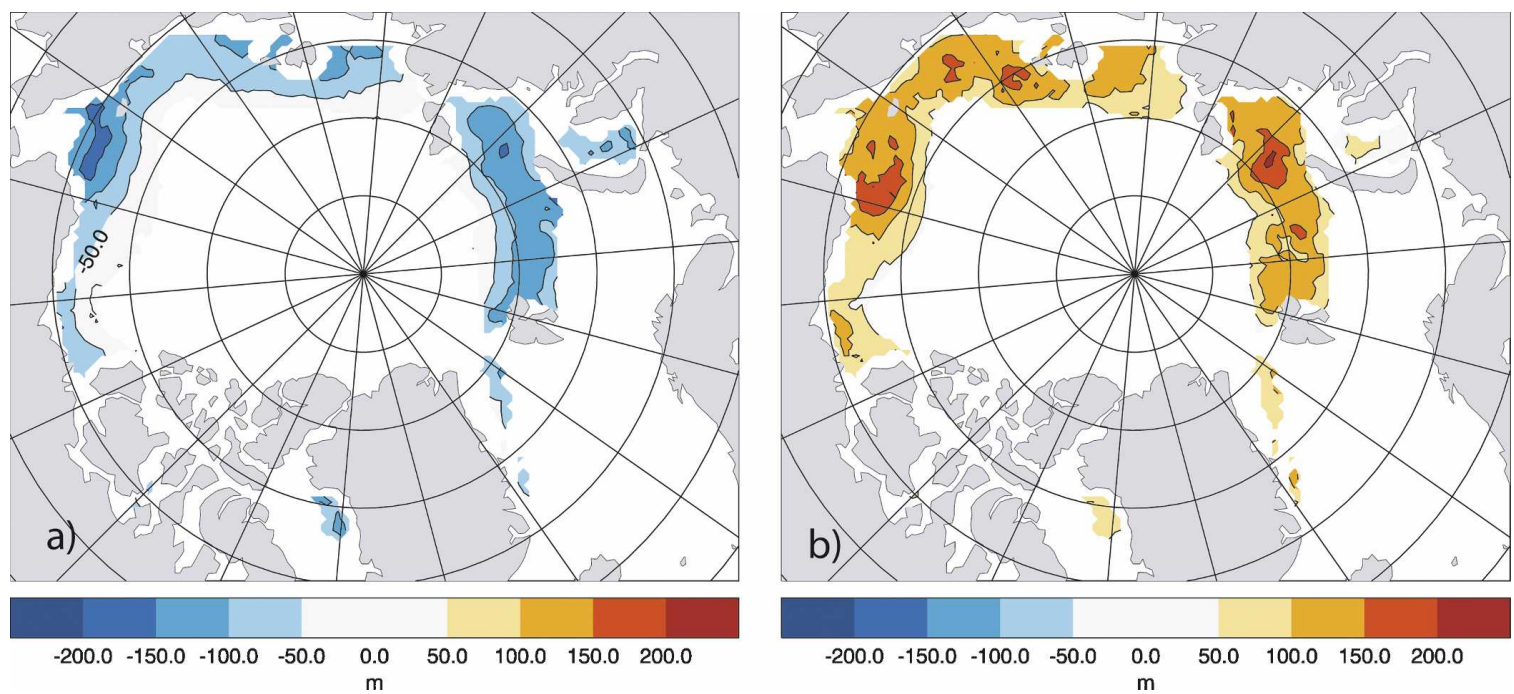

FIG. 9. Same as Fig. 6, but for composites of boundary layer height anomalies $\left(P_{g}>0.99, P_{f}>0.99\right)$.

play in retaining heat in the ice-ocean system, and thus contributing to the ice-albedo feedback? In contrast to many other areas of the world, clouds over Arctic sea ice provide a positive surface cloud forcing (warm the surface) except during a short period in summer when the surface albedo is low enough and the sun is high enough that the shading effect offsets an increase in longwave emission (Curry and Ebert 1992; Intrieri et al. 2002; Schweiger and Key 1994; Wang and Key 2005). During autumn, shortwave fluxes are small and cloud forcing is positive.

Assuming that cloud microphysical properties and cloud thickness are unchanged, the observed decrease in low cloud cover when ice concentrations are low

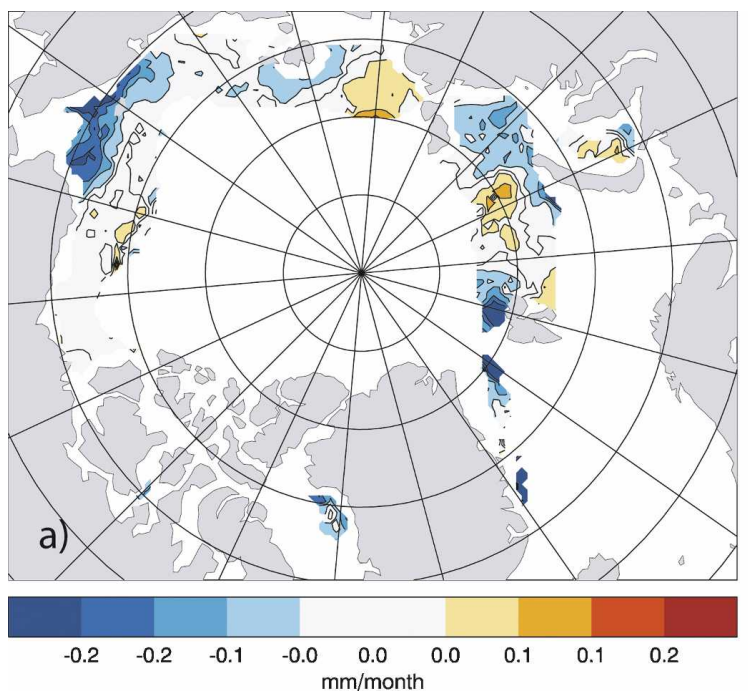

would reduce the downwelling longwave radiation. However, the simultaneous increase in middle-level clouds partially offsets this loss of downwelling longwave flux from the warmer low clouds

To illustrate this, we conducted a series of radiative transfer calculations using the "Streamer" forward radiative transfer model (Key and Schweiger 1998). A low water cloud was specified at $925 \mathrm{hPa}$, with a physical thickness of $200 \mathrm{~m}$ and droplet radius of $10 \mu \mathrm{m}$. The temperature and humidity profile was set to a mean autumn temperature profile over our study area derived from the ERA-40 data. The cloud fraction was varied by $10 \%$ to match the observed change in cloud cover. A $10 \%$ decrease in low cloud fraction alone re-

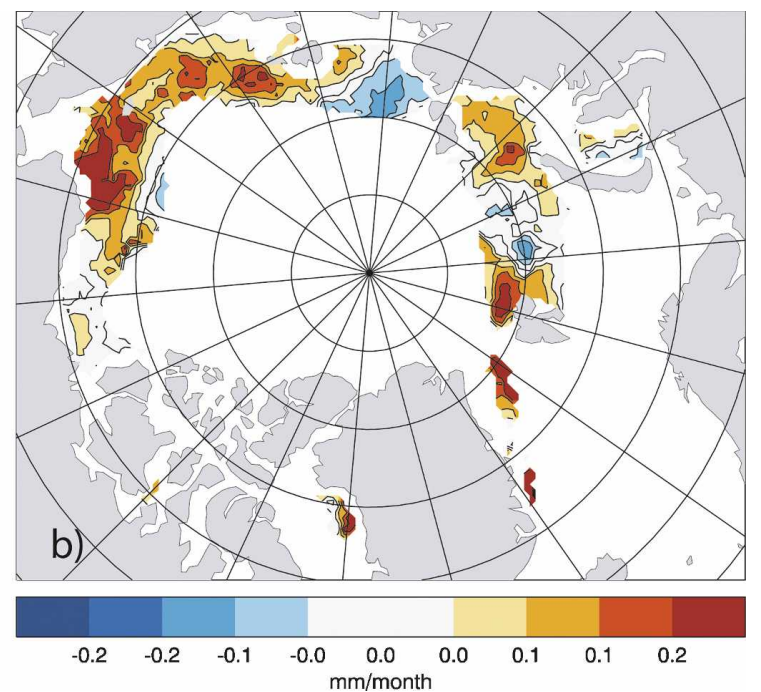

FIG. 10. Same as Fig. 6 but for composites of snowfall $\left(P_{g}>0.99, P_{f}>0.99\right)$. 

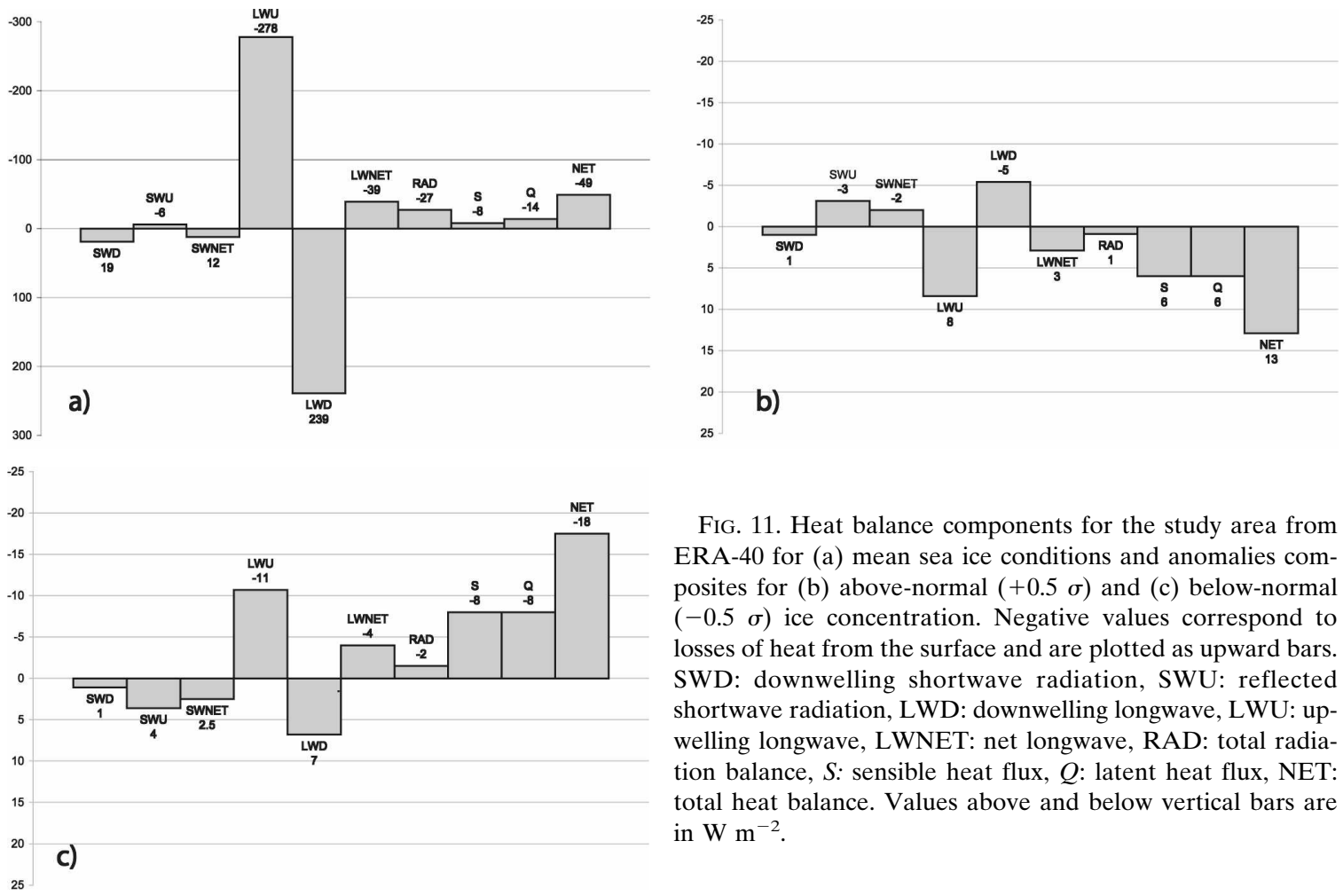

25

FIG. 11. Heat balance components for the study area from ERA-40 for (a) mean sea ice conditions and anomalies composites for (b) above-normal $(+0.5 \sigma)$ and (c) below-normal $(-0.5 \sigma)$ ice concentration. Negative values correspond to losses of heat from the surface and are plotted as upward bars. SWD: downwelling shortwave radiation, SWU: reflected shortwave radiation, LWD: downwelling longwave, LWU: upwelling longwave, LWNET: net longwave, RAD: total radiation balance, $S$ : sensible heat flux, $Q$ : latent heat flux, NET: total heat balance. Values above and below vertical bars are in $\mathrm{W} \mathrm{m}^{-2}$.

sulted in an $8 \mathrm{~W} \mathrm{~m}^{-2}$ decrease in downwelling longwave radiation. A midlevel cloud was inserted at 750 $\mathrm{hPa}$ and low cloud fraction was reduced from $65 \%$ to $55 \%$ while middle cloud fraction was increased from $25 \%$ to $35 \%$ to simulate the observed opposing changes in low and middle clouds. The overlap was held constant at $10 \%$ so that the total cloud fraction remained at $80 \%$. For this configuration the decrease in downwelling longwave was only $1 \mathrm{~W} \mathrm{~m}^{-2}$ because the radiative effects of changes in low and middle cloud fraction nearly cancelled.

Observations also indicated that temperature and humidity profiles were influenced by the varying ice cover: What is the radiative effect of this change? To isolate this effect alone, low and middle cloud amounts were fixed in the model while varying the temperature and humidity profiles (shown in Figs. 5 and 8). Changes in the profiles associated with above-normal ice versus less ice resulted in an increase in downwelling longwave radiation of about $6 \mathrm{~W} \mathrm{~m}^{-2}$. This is caused by an increase in the atmospheric emission (higher temperature) as well as the increase in cloud-base temperature due to the profile change (note that we kept cloud physical and microphysical properties constant). Clearly these values will vary depending on the assumptions about cloud macro- and microphysical properties, but they do illustrate the compensating effects of

changing cloud level combined with changes in the temperature/humidity profiles.

Even though the direct effect of cloud changes on the surface radiation is small, the sign of the radiative flux changes suggests that the observed cloud cover variations contribute to maintaining sea ice anomalies. While changes in cloud thickness or cloud microphysical properties have not been explicitly considered, those would have to be concurrent and of opposite sign with respect to their effect on downwelling longwave radiation to alter this conclusion. Future research will need to address this question in detail.

It is also possible that both sea ice and clouds are responding to the same external forcing. For example, advection of warm air may reduce ice growth and simultaneously cause the observed changes in vertical profiles and cloud heights. Although the direct radiative effect on the surface energy balance of changes in cloud cover constitutes a small negative feedback, the combined effect of changes in ice cover, vertical temperature structure, and cloud properties is more important. To further assess the changes in the surface energy balance associated with changes in ice concentration, the surface energy balance components from ERA-40 are also composited according to sea ice concentrations for the same area.

Figure 11 shows spatially averaged surface heat bal- 
ance components during autumn over our study area (again, only where the standard deviation of the sea ice concentration is greater than $10 \%$ ). Results are for mean sea ice conditions as well as anomaly composites for above- and below-normal sea ice $(+/-0.5 \sigma)$ concentration. During SON the longwave balance clearly dominates. Upwelling longwave fluxes exceed downward fluxes by $39 \mathrm{~W} \mathrm{~m}^{-2}$. Small sensible and latent heat losses from the surface are roughly balanced by shortwave gains. For above-normal sea ice conditions the net longwave losses are reduced by only $3 \mathrm{~W} \mathrm{~m}^{-2}$ owing to compensation by decreases in the downward longwave fluxes. Note that this occurs in spite of increases in low cloud cover, which would increase downwelling longwave radiation. It appears, however, that this is compensated by the radiative effect of middle cloud changes and the cooling of the lower parts of the boundary layer. Because longwave changes nearly cancel, the resulting changes in the surface heat balance associated with sea ice variability are dominated by turbulent fluxes, with a combined difference of about $31 \mathrm{~W}$ $\mathrm{m}^{-2}$ in the net surface heat balance between the composite averages. The net change in radiative fluxes is just $3 \mathrm{~W} \mathrm{~m}^{-2}$. It is important to note again that this analysis cannot diagnose the causative relationship. It does show, however, that even though changes in cloud cover associated with sea ice provide a small and negative direct feedback, simultaneous changes in temperature dominate the surface energy balance. The net cloud effect appears to be small, but changes in cloud liquid water path, base height, and phase have not been considered.

\section{Summary and conclusions}

We have documented an association between sea ice variability and cloud cover over marginal sea ice in the Arctic during autumn, along with associated changes in the atmospheric boundary layer and surface energy fluxes. When ice concentrations are lower, there are fewer low-level clouds and more midlevel clouds. The patterns of these changes are homogeneous within each composite and are clearly associated with the changes in ice cover. The same pattern is observed in satellitederived cloud data from the TPP project and is simulated by state-of-the-art GCMs (Vavrus et al. 2008, manuscript submitted to Climate Dyn.). The agreement between reanalysis and satellite data substantiates that the reanalysis model properly captures broad aspects of cloud variability and sets the stage for future, more detailed research into the physical mechanisms involved. Results presented here suggest that the observed change in cloud cover is caused by modifications to the temperature and humidity structure in associa- tion with the sea ice variability. When the sea ice cover is diminished during autumn, the temperature at the bottom of the boundary layer increases more than at the top, resulting in decreased static stability as well as weakening the climatological surface-based inversion that typically caps low cloud decks. The relative humidity at lower levels of the boundary layer is also reduced, while that at midlevels increases. Boundary layer height increases as sea ice decreases. The direct radiative effect of these changes in cloud cover constitutes a small negative feedback. The reduction in downwelling longwave fluxes associated with decreases in low-level clouds is offset by simultaneous increases in middle clouds as well as by surface and lower-level temperatures, so that changes in the longwave balance due to a decrease in sea ice are small. Changes in turbulent fluxes dominate the change in the surface heat balance during autumn.

Because the observed changes in cloud cover create a small negative feedback on sea ice growth (more downwelling longwave flux when there is more ice), we can discount the possibility that changes in cloud cover contribute to the sea ice anomalies in autumn. This result is in contrast with the conclusion of Francis and Hunter (2006), who find that during spring changes in cloud cover and resulting changes in downwelling longwave radiation are the primary drivers of subsequent sea ice reduction. So, while it appears that changes in cloud cover may have played a role in creating the sea ice anomalies during spring and summer, cloud feedbacks in response to the changed ice conditions do not contribute significantly to the maintenance of such anomalies during the autumn refreeze season. It is not at all surprising that processes may be different during different seasons and locations (e.g., see Francis and Hunter 2007).

Clearly, the simple analysis presented here cannot address the many complexities involved in cloud formation and dissipation, and many of them may not be realistically represented in the ERA-40 model. How sea ice interacts with cloud cover may very well depend on the synoptic situation and local conditions (e.g., persistent on-ice versus off-ice flow or varying ice thickness). The present analysis does demonstrate that a relationship exists, and it sets the stage for more detailed observational studies and for model experiments that allow for better control of specific variables. Our results also provide a starting point for a study into of the behavior of global climate models with respect to cloud-sea ice interactions. Based on the results presented here, sea ice-cloud feedbacks appear to have not played a significant role in the retention of summer heat in the ocean into the subsequent melt season. For 
the range of climate conditions observed from 1980 2001 , even though clouds seem to be responding to changing sea ice conditions, the radiative effect of this shift on the surface heat balance is small and if anything acts as a negative feedback. It remains to be seen if this conclusion holds as we see more dramatic changes in sea ice cover, such as those observed during the summer of 2007.

Acknowledgments. This work was supported by NSF Grant ARC-0629360 and NASA Grants NNG06GA76G, NNG06GA84, and NNG04GH52G. We thank NCAR for providing ERA-40 data and Mark Ortmeyer for processing the TPP data. Dick Moritz and Harry Stern are thanked for helpful suggestions. We are grateful to the three anonymous reviewers for their constructive comments.

\section{REFERENCES}

Beesley, J. A., and R. E. Moritz, 1999: Toward an explanation of the annual cycle of cloudiness over the Arctic Ocean. J. Climate, 12, 395-415.

Cavalieri, D. J., C. L. Parkinson, and K. Y. Vinnikov, 2003: 30year satellite record reveals contrasting Arctic and Antarctic decadal sea ice variability. Geophys. Res. Lett., 30, 1970, doi:10.1029/2003GL018031.

Comeaux, J. L., and J. Worley, 2005: ECMWF 45-Year Reanalysis Data from NCAR. Preprints, 21st Int. Conf. on Interactive Information Processing Systems (IIPS) for Meteorology, Oceanography, and Hydrology, San Diego, CA, Amer. Meteor. Soc., P2.34.

Curry, J. A., and G. F. Herman, 1985: Relationships between large-scale heat and moisture budgets and the occurrence of arctic stratus clouds. Mon. Wea. Rev., 113, 1441-1457.

- and E. E. Ebert, 1992: Annual cycle of radiation fluxes over the Arctic Ocean: Sensitivity to cloud optical properties. $J$. Climate, 5, 1267-1280.

- J. O. Pinto, T. Benner, and M. Tschudi, 1997: Evolution of the cloudy boundary layer during the autumnal freezing of the Beaufort Sea. J. Geophys. Res., 102C, 13 851-13 860.

ECMWF, 2003: Physical processes. Chapter 4, IFS Doc. CY 23R4, European Centre for Medium-Range Weather Forecasts, 166 pp.

Francis, J. A., and E. Hunter, 2006: New insight into the disappearing Arctic Sea ice. Eos, Trans. Amer. Geophys. Union, 87, 509 .

- and -2007 : Drivers of declining sea ice in the Arctic winter: A tale of two seas. Geophys. Res. Lett., 34, L17503, doi:10.1029/2007GL030995.

Herman, G., and R. Goody, 1976: Formation and persistence of summertime Arctic stratus clouds. J. Atmos. Sci., 33, 15371553.

Holland, M. M., and C. M. Bitz, 2003: Polar amplification of climate change in coupled models. Climate Dyn., 21, 221-232.

Intrieri, J. M., C. W. Fairall, M. D. Shupe, P. O. G. Persson, E. L. Andreas, P. S. Guest, and R. E. Moritz, 2002: An annual cycle of Arctic surface cloud forcing at SHEBA. J. Geophys. Res., 107, 8039, doi:10.1029/2000JC000439.

Key, J., 2000: The Cloud and Surface Parameter Retrieval (CASPR) system for polar AVHRR data user's guide. NOAA/NESDIS, $62 \mathrm{pp}$.

— transfer: Streamer and FluxNet. Comput. Geosci., 24, 443451.

Klien, S. A., and D. L. Hartmann, 1993: The seasonal cycle of low stratiform clouds. J. Climate, 6, 1587-1606.

Lindsay, R. W., and J. Zhang, 2005: The thinning of Arctic sea ice, 1988-2003: Have we passed a tipping point? J. Climate, 18, 4879-4894.

Liu, A. Q., G. W. K. Moore, K. Tsuboki, and I. A. Renfrew, 2006: The effect of the sea-ice zone on the development of boundary-layer roll clouds during cold air outbreaks. Bound.-Layer Meteor., 118, 557-581.

Liu, Y., J. R. Key, J. A. Francis, and X. Wang, 2007: Possible causes of decreasing cloud cover in the Arctic winter, 19822000. Geophys. Res. Lett., 34, L14705, doi:10.1029/ 2007GL030042.

Livezey, R. E., and W. Y. Chen, 1983: Statistical field significance and its determination by Monte Carlo techniques. Mon. Wea. Rev., 111, 46-59.

Maslanik, J. A., J. Key, C. W. Fowler, T. Nguyen, and X. Wang, 2001: Spatial and temporal variability of satellite-derived cloud and surface characteristics during FIRE-ACE. J. Geophys. Res., 106, 15 233-15 249.

Paluch, I. R., D. H. Lenschow, and Q. Wang, 1997: Arctic boundary layer in the fall season over open and frozen sea. J. Geophys. Res., 102, 25 955-25 971.

Pinto, J. O., 1998: Autumnal mixed-phase cloudy boundary layers in the Arctic. J. Atmos. Sci., 55, 2016-2038.

Schweiger, A. J., and J. R. Key, 1994: Arctic Ocean radiative fluxes and cloud forcing estimated from the ISCCP C2 cloud dataset, 1983-1990. J. Appl. Meteor., 33, 948-963.

, R. W. Lindsay, J. R. Key, and J. A. Francis, 1999: Arctic clouds in multiyear satellite data sets. Geophys. Res. Lett., $\mathbf{2 6}$ 1845-1848.

,-- J. A. Francis, J. Key, J. M. Intrieri, and M. D. Shupe, 2002: Validation of TOVS Path-P data during SHEBA. $J$. Geophys. Res., 107, 8041, doi:10.1029/2000JC000453.

Serreze, M. C., and Coauthors, 2003: A record minimum arctic sea ice extent and area in 2002. Geophys. Res. Lett., 30, 1110, doi:10.1029/2002GL016406.

, M. M. Holland, and J. Stroeve, 2007: Perspectives on the Arctic's shrinking sea-ice cover. Science, 315, 1533-1536.

Tiedtke, M., 1993: Representation of clouds in large-scale models. Mon. Wea. Rev., 121, 3040-3061.

Tsay, S. C., and K. Jayaweera, 1984: Physical characteristics of Arctic stratus clouds. J. Climate Appl. Meteor., 23, 584-596.

Uppala, S. M., and Coauthors, 2005: The ERA-40 re-analysis. Quart. J. Roy. Meteor. Soc., 131, 2961-3012.

Wang, Q., and S. P. Wang, 2004: Turbulent and thermodynamic structure of the autumnal Arctic boundary layer due to embedded clouds. Bound.-Layer Meteor., 113, 225-247.

Wang, X. J., and J. R. Key, 2005: Arctic surface, cloud, and radiation properties based on the AVHRR Polar Pathfinder dataset. Part I: Spatial and temporal characteristics. J. Climate, 18, 2558-2574. 